\title{
Studi Alih Fungsi Lahan Hutan Sagu Sebagai Perumahan Residence Di Kabupaten Jayapura
}

\author{
*Harina H. Ohee, Musfira \\ Fakultas Teknik Sipil dan Perencanaan, Universitas Sains dan Teknologi Jayapura \\ *email: fira.naja3@yahoo.com
}

\begin{tabular}{l} 
INFO ARTIKEL \\
\hline Riwayat Artikel: \\
Diterima: 06-02-2019 \\
Disetujui: $21-11-2019$
\end{tabular}

Kata Kunci:

Alih fungsi lahan

Hutan Sagu

Kampung Nendali

\begin{abstract}
ABSTRAK
Abstrak: Masalah tanah di daerah perkotaan merupakan persoalan tanah yang sangat kompleks, laju pertumbuhan penduduk yang tinggi,diiringi oleh pembangunan kawasan pemukiman, kawasan industri dan kawasan pertokoan yang menyebabkan tuntutan terhadap penyediaan tanah yang semakin meningkat. Sejalan dengan pemanfaatan tanah dan pengembangan tanah perkotaan memyebabkan sering terjadinya konflik atau permasalahan tanah. Kampung Nendali Distrik Sentani Timur adalah salah satu kampung yang mempunyai Lahan Hutan Sagu yang di lindungi dengan adanya Undang-undang perlindungan Hutan Sagu, dan daerah resapan air, masyarakat sekitar daerah proyek sangat terganggu dengan adanya proyek tersebut membuat mata pencharian dan pendapatan dari Sagu mulai berkurang, tangkapan ikan mulai berkurang, dan mencemari air bersih. Tujuan dari penelitian ini untuk mengidentifikasi faktor-faktor terkait regulasi dan pemberian ijin pembangunan Perumahan Residence Nendali City di Kawasan Lindung Hutan Sagu. Menganalisis dampak pembangunan perumahan Recidence Nendali City terhadapLingkungan dan Kondisi Sosial Masyarakat Kampung Nendali. Adapun metode analisa yang digunakan untuk menjawab tujuan penelitian adalah metode deskriptif, dimana metode deskriptif melingkupi reprensetatif terhadap gambaran objek pada lokasi studi. Penelitian tidak hanya terbatas pada tahapan pengumpulan data saja tetapi juga meliputi analisa serta pengolahan data. Sedangkan dalam penelitian ini di mulai dengan pengumpulan data secara kolektif yang di lakukan melalui survey dan observasi langsung pada lokasi studi yang mana sebelumnya dilakukan kajian pustaka sebagai bahan dasar teoritis.
\end{abstract}

\begin{abstract}
The problem of land in urban areas is very complex, a high rate of population growth, accompanied by the development of residential areas, industrial areas, and shopping areas, which causes demands for increased land supply. In line with land use and urban land development, it often causes conflicts or land problems. Nendali Village at East Sentani District is one of the villages that has Sago Forest Land protected by the Sago Forest Regulations, and water catchment areas, the community around the project area is very disturbed by the project, making livelihoods and income from Sago begin to decrease, fish catches began to decrease, and pollute clean water. The purpose of this study was to identify factors related to regulation and granting permission for the construction of Residence Nendali City in the Sago Forest Protected Area. Analyzing the impact of housing development in Resident Nendali City on the environment and social conditions of Kampong Nendali Community. The analytical method used to answer the research objectives is a descriptive method, where the descriptive approach encompasses repetitive assessment of the object at the study location. Research is not only limited to the data collection stage but also includes analysis and data processing. Whereas in this study began by collecting data collectively which was carried out through surveys and direct observations at the study location which are previously conducted a literature review as a theoretical basis
\end{abstract}

\section{A. LATAR BELAKANG}

Sejak masuk era reformasi di Indonesia, kota-kota di Provinsi Papua sejak satu dasawarsa ini, mengalami perubahan penggunaan lahan yang sangat pesat, perubahan ini akan tetap berlanjut dimasa yang akan datang. Pada umumnya perubahan penggunaan lahan yang terjadi di kawasan perkotaan hampir selalu tidak sesuai dengan rencana penggunaan lahan yang telah dituangkan dalam dokumen Rencana Tata Ruang Wilayah (RTRW).

Penggunaan lahan yang tidak sesuai dengan rencana (RTRW) yang ditetapkan atau dirumuskan sebelumnya merupakan gejala umun dan klasik terjadi di kota-kota yang memiliki laju pertumbuhan pesat. Alih fungsi lahan dari peruntukkan lahan yang direncanakan biasanya disebabkan oleh adanya ketimpangan antara pertimbangan yang mendasari arahan rencana 
sebagaimana yang dituangkan dalam dokumen RTRW dengan pertimbangan kebutuhan pengguna lahan. Alih fungus lahan yang menyimpang dari RTRW yang telah ditetapkan senantiasa terus terjadi dari waktu ke waktu. Perubahan ini dalam kurun waktu yang pendek, misalnya dalam periode tahunan rupanya tidak terlalu nampak. Perubahan penggunaan lahan baru tampak signifikan apabila dicermati atau dipelajari dalam kurun waktu yang relatif panjang (cukup lama), misalnya dalam kurun waktu paling kurang 10 tahun.

Kabupaten Jayapura merupakan salah satu kabupaten di provinsi Papua yang mana sejak Tahun 2002 sejak lahirnya kebijakan Otonomi Khusus bagi Tanah Papua merupakan kabupaten yang cukup pesat pembangunanya di Provinsi Papua. Secara yuridis Kabupaten Jayapura dimekarkan sesuai Undang-undang No. 26 Tahun 2002 menjadi 3 (tiga) kabupaten, yaitu Kabupaten Jayapura dengan Ibukota Sentani, Kabupaten Sarmi dengan Ibukota Sarmi dan Kabupaten Keerom dengan Ibukota Arso.

Pembangunan yang terjadi di Kabupaten Jayapura saat ini sangat mengancam kelestarian hutan sagu. Dimana sampai saat ini kawasan hutan sagu di Kabupaten Jayapura belum dilindungi Undang-Undang dengan maksimal. Hutan Sagu sudah sejak dahuluku kala menjadi sumber hidup masyarakat Papua Khususnya bagian pantai, selain itu keberadaan hutan sagu juga menjadi penyeimbang ekosistem dan penyeimbang ketersediaan air tanah. Hal ini tentulah sangat berbahaya jika pembangunan di Kabupaten Jayapura terus dilakukan tanpa memperhatikan kelesatarian hutan sagu yang mana dampak terhadap Lingkungan dan Aspek Sosial sangatlah besar.

Salah satu kampung di Kabupaten Jayapura yang gencar dengan pembangunan adalah Kampung Nendali. Kampung Nendali merupakan salah satu kampung yang masuk dalam wilayah administrasi Distrik Sentani Timur Kabupaten Jayapura Provinsi Papua, daerah dengan luas wilayah mencapai $5.672 \mathrm{~km}$ dengan jumlah KK yaitu 288. Berdasarkan Perda Kabupaten Jayapura No. 3 tahun 2000 tentang Pelestarian Hutan Sagu di Kabupaten Jayapura Kampung Nendali adalah salah satu daerah hutan sagu yang di lindung. Namun pada kenyataanya hutan sagu yang dilindungi ini terus dibabat habis tiap tahunya untuk kepentingan pembangunan perumahan, pelebaran jalan, dan fasilitas umum lainya.

Salah satu pembangunan perumahan yang membutuhkan lahan mancapai 5 hektar di Kampung Nendali adalah Perumahan Residence Nendali City dari total lahan hutan Sagu berjumlah 25 hektar yang kepemilikan lahannya telah berpindah tangan dari ondoafi selaku pemegang hak ulayat ke PT Sagita telah membeli 19 hektar lahan hutan Sagu dan tersisa 6 hektar.
Berdasarkan data Profil Kampung Nendali tahun 2016 tercatat bahwa 80\% Penduduk Kampung Nendali berprofesi sebagai petani dan nelayan yang mana masuk kategori penduduk berpenghasilan rendah. Melihat kondisi ini dan dengan nilai jual tanah yang sangat mahal sudah tentu masyarakat akan memilih menjual tanah untuk memperoleh uang dalam memenuhi kebutuhan ekonomi mereka dibandingan harus mengelola hutan sagu yang mana penghasilnya tidak seberapa dalam waktu singkat. Dengan pola pikir seperti ini sangatlah sulit mencegah pembangunan yang terus menggusur hutan sagu dimana kebutuhan masyarakat dan kebijakan pemerintah daerah terkait pengelolaan hutan sagu saling bertolak belakang karena masingmasing pihak yang berkepentingan memiliki rencana yang berbeda satu sama lain. Pembangunan Perumahan Residense Nendali City di lahan hutan sagu menjadi pertanyaan kepada pemerintah Daerah, Bagaimana bisa pemberian ijin pembangunan dapat di keluarkan yang mana Pemerintah Daerah Sendiri yang membuat kebijakan pengelolaan hutan sagu ini. Melihat kondisi ini penulis tertarik mengangkat sebuah penelitian terkait pembangunan Perumahan Residence Nendali City di Kawasan Hutan Sagu yang tentunya merupakan tindakan alih fungsi lahan yang mana akan berdampak pada lingkungan, kondisi sosial budaya dan ekonomi masyarakat di Kampung Nendali dan Sekitarnya.

Tujuan dari penelitian ini adalah untuk mengidentifikasi faktor-faktor terkait regulasi dan pemberian izin pembangunan perumahan residence Nendali City di kawasan lindung hutan sagu. Menganalisis dampak pembangunan perumahan recidence Nendali city terhadaplingkungan dan kondisi sosial masyarakat kampung Nendali

\section{B. METODE PENELITIAN}

Metode yang digunakan adalah metode deskriptif, dimana metode deskriptif melingkupi reprensetatif terhadap gambaran objek pada lokasi studi. Penelitian tidak hanya terbatas pada tahapan pengumpulan data saja tetapi juga meliputi analisa serta pengolahan data. Sedangkan dalam penelitian ini di mulai dengan pengumpulan data secara kolektif yang di lakukan melalui survey dan observasi langsung pada lokasi studi yang mana sebelumnya di lakukan kajian pustaka sebagai bahan dasar teoritis. Lokasi Penelitian di Kampung Nendali adalah salah satu Kampung yang terletak di wilayah Distrik Sentani Timur Kabupaten Jayapura dengan luas wilayah $5,672 \mathrm{Km}^{2}$ dengan batasbatas wilayah kampung sebagai berikut, Sebelah Utara berbatasan dengan Distrik Rafenirara, Sebelah Selatan berbatasan dengan Danau Sentani, Sebelah Timur berbatasan dengan Kampung NoloklaSebelah Barat berbatasan dengan Kelurahan Sentani Kota, Jika dilihat dari letak geografisnya Kampung Nendali termasuk daerah daratan dengan kemiringan tanah $0-5 \%$ dan $5^{-}$ 
15\%. Metode Pengumpulan data yaitu Pengumpulan Data Primer, Wawancara merupakan proses pengumpulan data dan informasi yang dilakukan untuk memperoleh data secara langsung. Wawancara pada studi ini menggunakan teknik wawancara terstruktur, dengan mengajukan pertanyaan secara lisan kepada orang-orang yang dianggap mempunyai pengaruh serta pengalaman seperti Kepala Dinas BLH, Bapeda Kabupaten Jayapura, Kepala Kampung Nendali, Tokoh Masyarakat Adat, Observasi adalah bagian dari proses pengumpulan data primer, yang mempunyai ciri yang spesifik bila di bandingkan dengan teknik-teknik yang lain, yang selalu berkomunikasi langsung kepada orangorang yang berpengaruh, hal ini beda dengan wawancara yang tidak terbatas pada orang-orang, tetapi juga obyekobyek lain yang berkaitan dengan permasalahan yang dibahas pada penulisan ini dimana data dan informasi yang diperoleh dengan cara mengamati langsung pengelolaan dan pemanfaatan ruang serta pelestarian hutan lindung yang ditetapkan oleh Pemerintah daerah di Kampung Nendali Distrik Sentani Timur Kabupaten Jayapura.

Kuosioner bagian dari proses pengumpulan data primer, merupakan proses pengumpulan data dan informasi yang dilakukan untuk memperoleh data secara langsung dengan mengunakan kuisioner yang berisi pertanyaan mengenai dampak permasalahan yang dirasakan dan obyek-obyek lain yang berkaitan dengan permasalahan yang dibahas pada penulisan ini. Pengumpulan Data Sekunder yaitu Data atau informasi yang di peroleh dari survey deskriptif perpustakaan, dengan tujuan memperoleh dan mengumpulkan semua sumber pustaka yang berkaitan dengan judul penelitian dan juga yang diperoleh dari instansiinstansi terkait (Data Instansional) dimana data yang di butukan meliputi RTRW Kabupaten Jayapura, RDTR Ibukota Kabupaten Jayapura, Profil Distrik Sentani Timur dan RPJM Kampung Nendali. Analisa penentuan sampel bertujuan untuk mengetahui banyaknya sampel yang dapat dijadikan responden untuk penyebaran kuisioner pada di Kampung Nendali guna menggali informasi yang dibutuhkan. Proyeksi jumlah penduduk perlu dilakukan untuk mengetahui jumlah penduduk pada masa akan datang di Kampung Nendali. Analisa Kesesuaian Lahan: Ruang yang mempuyai tiga jenis pengunaan ruang dan pengunaan ruang yang mempunyai peran dan fungsinya masing-masing agar tercipta kehidupan yang dinamis antara manusia dan alam. Jenis pola ruang tersebut adalah kawasan lindung, kawasan penyangga, dan kawasan budidaya. Untuk menentukan fungsi suatu kawasan dibutuhkan data fisik, suatu wilayah yaitu kelereng, jenis tanah dan intensitas hujan dan ketiga indikator mempunyai bobot skor masing masing berdasarkan SK Menteri Pertanian nomor 837/KPTS/UM/11.190.

\section{HASIL DAN PEMBAHASAN}

Kondisi geologi dan jenis tanah di kawasan Studi Kampung Nendali adalah jenis tanah tersebut antara lain podsolik, podsolik, organosol dan latosol yang menunjukkan bahwa kawasan wisata mempunyai kondisi tanah yang relatif subur sehingga dapat pula dimanfaatkan sebagai kawasan budidaya. Selain itu, dengan kondisi geologi dan jenis tanah tersebut. Secara garis besar, persentase luas wilayah Ibukota Kabupaten Jayapura berada pada topografi datar (o-8\%) hingga sangat curam (lebih dari 45\%). Kemiringan lahan datar o-8\% dan 8-15\% paling banyak terdapat di wilayah Ibukota Kabupaten Jayapura. Kemiringan lereng tersebar di semua distrik, kelerengan $>45 \%$ tidak terdapat hanya di Distrik Ebungfauw dari luas total wilayah kawasan wisata. Hal ini merupakan salah satu potensi untuk pengembangan kawasan wisata karena dengan topografi yang relatif datar maka biaya pengembangan kawasan relatif lebih murah karena tidak diperlukan lagi biaya pematangan lahan. Tetapi yang menjadi pertimbangan adalah kemiringan $>45 \%$ ke arah Utara dari ke tiga distrik yang termasuk dalam kawasan wisata terpadu yaitu distik sentani timur, sentani dan wiabu, sebelah utara dari ke tiga distrik ini adalah kawasan cagar alam cycloop (kawasan lindung).

\section{Regulasi Dan Pemberian Ijin}

Forum kerja sama Swadaya Masyarakat (FlokerLSM) Papua menyesalkan penebangan Hutan Sagu sepanjang Kampung Nendali Sentani Kabupaten Jayapura. Hutan Sagu Papua yang kini tersisa yaitu 3,7 hektar itupun terancam pembabatan. Hutan Sagu secara perlahan kini di ganti dengan tanaman lain maupun di alih fungsikan ke kawasan Pemukiman dan industri. Padahal sagu merupakan tanaman lokal bagi masyarakat dan kondisi alam Papua. Sagu pun sesuai dengan program kedaulatan pangan. Hutan Sagu tidak tidak merusak lingkungan, justru kalo hutan sagu di babat dan di ganti dengan tanaman lain maupun pembangunan tidak akan mengantikan peran Hutan Sagu yang sangat besar manfaatnya dalam kehidupan sebagai sandang pangan papan, dan sebagai salah satu tumbuhan penyumbang Oksigen terbesar.

Pemerintah telah mengeluarkan Perda Nomor 3 . Tahun 2000 tentang pelestarian Kawasan kawasan Hutan Sagu tetapi hal tersebut hanya di buat tetapi tidak di jalankan oleh masyrakat maupun Stakeholder karena pemerintah hanya mengeluarkan Perda pelarangan tetapi tidak ada hukum atau sangsinya jdi masyarakat dan pengusaha tidak terlalu menaati Perda nomor 3 tahun. Pemerintah telah melakukan bersosialisai tahun 2011 di kampung Nendali Distrik Sentani Timur tentang perlindungan Hutan Sagu hingga memasang papan pelarangan tetapi masyakat tidak mematuhi peraturan dan peringatan dan Kepala Bapeda Kab Jayapura mengatakan bahwa Sagita telah melangar peraturan pemerintah, dan tidak boleh membangun karena tidak sesuai dengan arahan fungsi ruang, dan pendapat kepala BLH Kab jayapura bahwa, Kegiatan pembangunan dan penampungan matrerial PON, itu berdampak buruk karena air pembuangan dari mencuci material di alirkan ke danau, dan polusi karena proyek keluar masuk 24 jam. 


\section{Analisa Kesesuaian Lahan}

Berdasarkan hasil klarifikasi nilai skor dan faktor jenis tanah menurut kepekaanya terhadap erosi, maka dapat diketahui jenis tanah yang berada pada lokasi studi berupa jenis tanah Podsolikdengan nilai 75. Jenis tanah ini merupakan jenis tanah yang lebih dominan berada pada kelerangan $0-35 \%$ maka kawasan ini termasuk kawasn budidaya. Wilayah Distrik Sentani Timur yang topografinya adalah dataran rendah dapat dijadikan lahan untuk pertanian, perkebunan, permukiman dan berbagai aktifitas sosial dan ekonomi penduduk. Dengan kondisi fisik yang demikian, maka biaya pengembangan wilayah dapat diminimalisir, tidak membutuhkan biaya besar seperti membangun di daerah yang topografinya berbukit atau gunung.

Tabel 4.1

Kriteria Kawasan Distrik Sentani Timur

\begin{tabular}{|c|c|c|c|c|c|c|c|c|}
\hline \multirow{2}{*}{ No } & \multicolumn{2}{|c|}{ Topografi } & \multicolumn{2}{c|}{ Jenis Tanah } & \multicolumn{2}{c|}{ Curah Hujan } & \multirow{2}{*}{ Jumlah } & Fungsi Kawasan \\
\cline { 2 - 7 } & Nilai & Bobot & Nilai & Bobot & Nilai & Bobot & & \\
\hline 1 & $0 \%-8 \%$ & 20 & Podsolik & 15 & $<13.6$ & 10 & 45 & Kawasan permukiman dan jasa \\
\hline 2 & $0 \%-8 \%$ & 20 & Podsolik & 75 & $<13.6$ & 10 & 105 & Kawasan budidaya tanaman tahunan \\
\hline 3 & $8 \%-15 \%$ & 40 & Podsolik & 15 & $<13.6$ & 10 & 65 & Kawasan Budidaya Semusim/ Permukiman \\
\hline 4 & $8 \%-15 \%$ & 40 & Orgosol & 75 & $<13.6$ & 10 & 125 & Kawasan Budidaya Tanaman Tahunan \\
\hline 5 & $25 \%-45 \%$ & 80 & Orgosol & 75 & $<13.6$ & 10 & 165 & Kawasan Penyangga \\
\hline 6 & $>45 \%$ & 100 & Orgosol & 75 & $13.6 \%$ & 10 & 185 & Kawasan Lindung \\
\hline
\end{tabular}

Sumber: Hasil Analisa

Luas keseluruhan Distrik Sentani Timur adalah ebesar 10.302,06 Ha. Dari total luas Distrik Sentani Timur, lahan yang terbangun adalah sebesar 390,18 Ha atau sebesar $12 \%$ dengan penggunaan lahan terbesar adalah untuk permukiman sebesar 9\% dan terkecil adalah perdangangan dan jasa yaitu sebesar $0,3 \%$. Dengan demikian didapatkan hasil bahwa 9,223 $\mathrm{Ha}$ atau sebesar $76 \%$ lahan yang belum terbangun, lahan ini didominasi oleh hutan lindung, hutan sekunder dan alang- alang. Sesuai dengan arahan penataan rencana pola ruang, maka lahan yang dapat digunakan untuk pembangunan adalah $59,4 \%$.

Dengan luas hutan yang mendominasi, maka diperlukan pembangunan yang berwawasan lingkungan agar tidak menggangu keseimbangan lingkungan. Berdasarkan hasil analisis kesesuaian lahan yang telah dilakukan, untuk peruntukan kawasan lindung setempat khususnya disepanjang bantaran sungai di Kawasan Perkotaan Sentani seharusnya tidak digunakan untuk perkembangan bangunan. Pada wilayah tersebut dapat dikembangkan sebagai area barrier dengan ditanami tumbuh-tumbuhan penguat tanggul agar tidak mudah tergerus oleh aliran sungai ketika terjadi run off di musim penghujan. Selain bantaran sungai, juga terdapat kawasan sempadan danau dan pantai yang berfungsi sebagai kawasan lindung. Dari keseluruhan luas lahan Distrik SentaniTimur hampir kurang lebih 10-20 hektar yang mengalami masalah peruntukan yang tidak sesuai dari keseluruhan luas wilayah Distrik Sentani Timur yaitu 10,302 Ha. Adapun pemasalah yang ada di lokasi studi beedasarkan hasil survei di lapangan adalah:

\section{a. Pengetahuan masyarakat yang masih rendah}

Rendahnya pengatahuan masyarakat tetang pemanfaatan ruangyang berakibat pada kurangnya rasa memiliki masyarakat terhadap program-program yang dijalankan pemerintah untuk pengembangan
ruang.Masalah rendahnya pengetahuan masyarakat dapat dilihat pada permukiman masyarakat yang di bangun pada kawasan hutan sagu dan pembukanperkebunan rakyat pada kawasan hutan penyanga serta sepadan danau.Dari keseluruhan jumlah penduduk yang ada di Distrik Sentani Timur yang bertempat tinggal juga di Distrik Sentani Timur sebagian penduduk tetap, hampir 60\% masyarakat khususnya yang berkerja sebagai buruh, petani, nelayan dan penambang sebagian besar belum memahami tentang pengetahuan tata ruang yang direncanakan akibat kurangnya sosialisasi pemerintah kepada masyarakat.

\section{b. Pembukaan Lahan baru}

Banyak pembukaan lahan baru yang peruntukannya belum ada dalam perencanaan pengembangan Kampung bahkan banyak lahan baru yang di buka berada pada daerah hutan lindung, hutan konservasi, daerah rawan bencana dan daerah-daerah yang di lindungi lainnya. Pembukaan lahan baru yang terjadi di Distrik Sentani Timur kurang lebih 2-3 hektar yang berakibat pada terjadinya longsor yang tejadi apabila terjadi hujan yang cukup deras.

\section{c. Pembukaan lahan untuk perkebunan rakyat}

Banyak pembukaan lahan baru yang digunakan masyarakat untuk membuat kebun, seperti kebun pisang, ubi-ubian, sayur- sayuran dan lain sebagainya yang akan berdampak pada rusaknya hutan penyangga yang memelihara pertumbuhan ekositem dan sumber air di Distrik Sentani Timur, dan dampak lain yang timbul juga adalah terjadi longsor dan banjir.

Pembukan lahan oleh masyarakat yang bermatapencaharian sebagi petani dan penambang pada umumnya dilakukan oleh masyrakat asli yang memiliki hak ulayat terbesar di Distrik Sentani Timur.Pembukaan lahan baru untuk perkebunan hampir terdapat di seluruh Wilayah Pengembangan.Kurang lebih 408,32 Ha atau sekitar 
dari keseluruhan Distrik Sentani Timur yaitu 10,302 Ha yang terdapat pembukaan lahan untuk perkebunan

\section{Analisa Dampak Lingkungan}

Kampung Nendali saat ini sangat memprihatinkan karena adanya pembangunan perumahan dan penampungan material PON daerah yang dulunya hutan sagu sebagai makanan pokok dan sumber pendapatan bagi masyarakat sentani kini sudah bukan lagi hutan sagu tetapi sudah berubah menjadi kawasan pemukiman dan bahan material proyek yang membuat banyak masyarakat kampung resah dan merasa hutan sagu. Selain itu, danau sebagai sumber air bersih teracam kualitasnya. Air Danau yang biasanya digunakan warga sebagai sumber air dan mencari ikan sekarang mulai berkurang jumlah ikannya karena banyak yang mati akibat tercemarnya air di sekitar danau. Selain itu, aktivitas proyek pembangunan perumahan dan penampungan material PON membuat udara tercemar. Debu beterbangan dari aktivitas pra konstruksi dan konstruksi membuat warga sekitar terganggu.

Semenjak adanya pembangunan di Kampung Nendali dan menimbun lahan hutan sagu yang merupakan daerah rawa atau daerah resapan air, mengakibatkan saat ini sering terjadi genangan air dan ada sungai atau mata air kecil dalam lokasi studi yang dipaksa timbun hingga airnya meluap keluar terjadinya genangan sehingga pihak proyek harus setiap kali menimbun lokasi ini. Genangan ini terjadi saat mereka menimbun kawasan hutan sagu yang mana adalah daerah resapan air dan di daerah ini pun ada mata air atau kali kecil yang bermuara ke danau tapi sayangnya kali tersebut sudah ditimbun aliran yang akan ke danau maka dari itu terjadi genangan yang tidak pernah hilang karena daerah yang harusnya alur air mengalir di timbun oleh material.

Ketinggian air yang tergenang setingi mata kaki dan kini mencapai batas paha orang dewasa. Masalah yang terjadi di lokasi adalah tanah tersebut semakin turun jika di bangun dan daerah resapan air, dan masalah berikutnya genangan sehingga air yang harusnya bermuara ke danau di timbun jadinya air tertahan dan berputar di tempat lokasi pembangunan saja tidak mengalir ke danau.

\section{Dampak Sosial budaya}

Kehidupan sosial keagamaan di Kampung Nendali cukup kondusif dan baik. Dimana mayoritas penduduk Kampung Nendali beragama Kristen Protestan. Kehidupan Sosial Masyarakat sehari-hari masih kental dengan budaya timur yang mempertahankan semangat gotong royong dan bekerja sama dalam berbagai bidang, baik dalam hal pekerjaan fisik bangungan, berkebun, berburu sampai kepada pembayaran adat baik itu mas kawin atau kepala masih menjadi ciri khas kehidupan masyarakat Kampung Nendali sehari-hari. Fenomena pendidikan di Kampung Nendali memang cukup maju, tetapi itu tidaklah merata pada semua kalangan karena hanya golongan menengah yang mengalami sementara bagi kalangan bawah harus putus sekolah atau berhenti di tingkat SD \& SLTP.

a. Menimbulkan kerusakan lingkungan dan kelangsungan ekosistem alam. b. Mengakibatkan adanya kesenjagan social yang kemudian menjadi penyebab munculnya penyakit social, termasuk tingginya tingkat kriminalitas.

c. Mengurangi bahkan dapat menghilangkan ikatan batin dan moral yang biasanya dekat dalam hubungan sosial antar masyarakat.

\section{SIMPULAN DAN SARAN}

Dari hasil analisa dan pembahasan, maka dapat disimpulkan bahwa pembangunan Perumahan Residence dan Penampungan Material Pon di Kampung Nendali Distrik Sentani Timur belum layak atau tidak tepat dijadikan kawasan Perumahan Residence karena sehingga secara khusus dapat disimpulkan sebagai berikut :

1. Berdasarkan hasil analisa Populasi Dan Sampel dimana menujukan bahwa masyarakat di Kampung Nendali sangat tidak merasakan dampak yang baik, hanya untuk satu dua orang saja yang merasakan dampak postif dari pembangunan perumahan Residence karena mempunyai lapangan pekerjaan dan masyarakat kampung Nendali lainya tertentu merasakan dampak buruk bagi masyarakat sekitar dan merugikan banyak masyarakat dari mata pencarian sampai ke lingkungan mereka tinggal

2. Berdasarkan analisa Keseuaian Lahan dan bahwa daerah tersebut adalah daerah yang tidak boleh ada pembangunan diatas lahan Hutan Sagu karena sudah menyalahi aturan dan tekstur tanah tidak sesuai untuk dibangun

3. Berdasarkan Analisa Komparatif Pembangunan di Kampung Nendali sangat tidak tepat karna tidak melihat arahan Tata Ruang, perda dan Undang undang yang tekait dengan peraturan pembangunan dan dampak yang merugikan masyarakat

4. Faktor Masyarakat Kampung Nendali Menjual Lahan Hutan Sagu. Berdasarkan hasil Wawancara saya bersama Bapak Neles Taime salah satu warga yang berperan penting dalam penjualan Tanah tersebut, Bapak mengatakan Bahwa mereka menjual atas dasar faktor Ekonomi dan hal ini kesepakatan mereka bersama Ondoafi di kampung Nendali karena dijanjikan oleh pihak pengembang/developer selaku pemilik proyek tersebut akan membangun rumah adat dan membuka lapangan kerja bagi masyarakat Kampung Nendali.

\section{DAFTAR RUJUKAN}

[1] Undang-undang Nomor 3 Tahun 2000 tentang Perlindungan Hutan Sagu

[2] UU No.1 tahun 2011 tentang perumahan dan kawasan pemukiman, permukiman

[3] Undang Undang Tata Ruang Republik Indonesia Nomor 26 Tahun 2007 Tentang Penataan Ruang dan rencana Tata Ruang Nasional

[4] Undang Undang Perumahan dan permukiman Republik Indonesia Nomor 1 Tahun 2011 tentang Perumahan dan kawasan permukiman

[5] Undang Undang Perumahan dan permukiman Republik Indonesia Nomor 1 Tahun 2011 tentang Perumahan dan kawasan permukiman 
94 | Jurnal Planoearth | Vol. 4, No. 2, Agustus 2019, hal 89-94

[6] Undang Undang Nomor 32 Tahun 2009, Tentang Perlingdungan Pengelolaan Lingkungan Hidup.

[7] RTRW Kabupaten Jayapura 